\title{
Structural Concrete Prepared with Coarse Recycled Concrete Aggregate: From Investigation to Design
}

\author{
Valeria Corinaldesi \\ Engineering Faculty, Universitá Politecnica delle Marche, Brecce Bianche Street, 60131 Ancona, Italy \\ Correspondence should be addressed to Valeria Corinaldesi, v.corinaldesi@univpm.it \\ Received 28 February 2011; Accepted 24 August 2011 \\ Academic Editor: Paulo Monteiro
}

Copyright () 2011 Valeria Corinaldesi. This is an open access article distributed under the Creative Commons Attribution License, which permits unrestricted use, distribution, and reproduction in any medium, provided the original work is properly cited.

\begin{abstract}
An investigation of mechanical behaviour and elastic properties of recycled aggregate concrete (RAC) is presented. RACs were prepared by using a coarse aggregate fraction made of recycled concrete coming from a recycling plant in which rubble from concrete structure demolition is collected and suitably treated. Several concrete mixtures were prepared by using either the only virgin aggregates (as reference) or 30\% coarse recycled aggregate replacing gravel and by using two different kinds of cement. Different water-to-cement ratios were adopted ranging from 0.40 to 0.60 . Concrete workability was always in the range $190-$ $200 \mathrm{~mm}$. Concrete compressive strength, elastic modulus, and drying shrinkage were evaluated. Results obtained showed that structural concrete up to C32/40 strength class can be manufactured with RAC. Moreover, results obtained from experimentation were discussed in order to obtain useful information for RAC structure design, particularly in terms of elastic modulus and drying shrinkage prediction.
\end{abstract}

\section{Introduction}

Crushing concrete to produce coarse aggregate for the production of new concrete is one common means for achieving a more environmentally friendly concrete. Recycling concrete wastes will lead to reduction in valuable landfill space and savings in natural resources. In fact, the use of recycled aggregate concrete (RAC) is acquiring particular interest in civil construction as regards to sustainable development.

Many studies demonstrate the feasibility of the use of crushed concrete as coarse aggregates [1-10], its use being already accounted for in the regulations of many countries. In Italy, the use of $30 \%$ recycled concrete instead of virgin aggregate is definitively allowed for producing structural concretes (up to C 30/37 strength class) since July 2009 [11]. Nevertheless, in the Italian regulations no indication about predictions of RAC elastic modulus and drying shrinkage is reported. The study of the elastic behaviour of concretes made of 30\% recycled-concrete aggregates, discussed here, just had the aim to provide useful information.

\section{Experimental Program}

2.1. Materials. Two commercial portland-limestone blended cements were alternatively used, type CEM II/A-L $42.5 \mathrm{R}$ and type CEM II/B-L $32.5 \mathrm{R}$ according to EN-197/1 [12] (the main difference is the content of calcium carbonate that in the first case is less than $20 \%$ and in the second case is included in the range $21-35 \%$ according to EN-197/1). The Blaine fineness of cements were $0.42 \mathrm{~m}^{2} / \mathrm{g}$ and $0.40 \mathrm{~m}^{2} / \mathrm{g}$, respectively, and their specific gravity were $3.05 \mathrm{~kg} / \mathrm{m}^{3}$. The first kind of cement (i.e., CEM II/A-L $42.5 \mathrm{R}$ ) due to its composition and its higher fineness is expected to perform more than the other.

Quartz sand $(0-5 \mathrm{~mm})$, fine gravel $(6-12 \mathrm{~mm})$, and gravel (11-22 mm) were used, suitably combined, for preparing the reference mixtures. Their main physical properties were evaluated according to EN 1097-6 [13] and reported in Table 1 and their gradations evaluated according to EN 933-1 [14] are shown in Figure 1.

In addition, a coarse recycled aggregate fraction (11$22 \mathrm{~mm}$ ) was used, coming from a recycling plant in which 
TABLE 1: Main physical properties of the aggregate fractions.

\begin{tabular}{lcccc}
\hline Aggregate fractions & Quartz sand & Fine gravel & Gravel & Coarse recycled fraction \\
\hline Relative specific gravity (SSD) & 2.540 & 2.560 & 2.570 & 2.420 \\
Water absorption (\%) & 3.5 & 3.0 & 3.0 & 6.8 \\
\hline
\end{tabular}

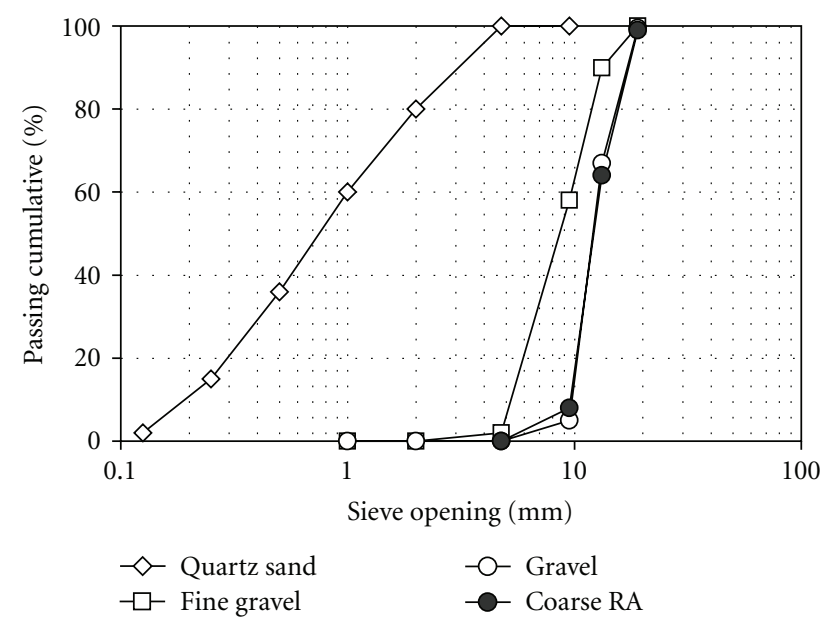

FIgURE 1: Grain size distribution curves of the aggregate fractions.

rubble from concrete structure demolition is suitably treated. Its composition is $100 \%$ recycled concrete; the original concrete strength class was unknown and likely different for waste concrete coming from different sources. The main physical properties of the recycled aggregate fraction are reported in Table 1, and its gradation is shown in Figure 1. The content in recycled concrete fraction of chlorides, sulphates, and organic materials were evaluated according to the methods recommended by UNI EN 1744-1 (part 7, $11,12,14$, and 15) [15] and the presence of alkali-silica reactive materials according to the method recommended by UNI EN 8520-22 [16]. No organic or alkali-silica reactive materials were detected; concerning the amount of chlorides and sulphates they were below the threshold value of $0.04 \%$ (by weight) and $0.15 \%$ (by weight), respectively.

As a-water-reducing admixture, a $30 \%$ aqueous solution of carboxylic acrylic ester polymer was added to the mixtures.

2.2. Concrete Mixture Proportions. The concrete mixture proportions of the reference mixtures (REF) made of $100 \%$ virgin aggregates and of the mixtures made of 30\% coarse recycled aggregate replacing gravel (CRA) are reported in Tables 2 and 3, respectively. The recycled-aggregate fraction was added to the mixture after water soaking, in a condition very close to that defined as saturated surface dried. In fact, on the basis of the results obtained in a previous work [17], it seems that presoaked aggregates can be more effective in order to create an internal water supply able to reduce drying shrinkage as well as to avoid water absorption of aggregate during mixing and, consequently, to maintain concrete workability for enough time to be cast.
Five different water-to-cement ratios were adopted when the cement type CEM II/A-L $42.5 \mathrm{R}$ was used: 0.40, 0.45, $0.50,0.55$, and 0.60 . On the other hand, the study was limited to three water-to-cement ratios when the cement type CEM II/B-L 32.5 R was used: 0.40, 0.50, and 0.60.

All the concrete mixtures showed the same fluidity level (S5, slump in the range 190-200 mm), evaluated according to EN 12350-2 [18].

In order to optimize the grain size distribution of the solid particles in the concrete, the aggregate fractions were suitably combined according to the Bolomey particle size distribution curve [19].

A water-reducing admixture was always added to the mixtures but at different dosages, ranging from $1.2 \%$ to $0.4 \%$ by weight of cement in order to adjust cement dosage (always kept under $350 \mathrm{~kg} / \mathrm{m}^{3}$ and gradually decreased for increasing water to cement ratios). In fact, in the current practice concretes with water/cement of 0.40 are typically prepared with about $350 \mathrm{~kg} / \mathrm{m}^{3}$ of cement and concretes with water/cement of 0.60 with roughly $300 \mathrm{~kg} / \mathrm{m}^{3}$ of cement.

2.3. Preparation and Curing of Specimens. Thirty cubic specimens, $100 \mathrm{~mm}$ in size, were cast in steel forms for each concrete mixture for compression tests, according to UNI EN 12390-1 [20] and wet cured at $20^{\circ} \mathrm{C}$.

In addition, three prismatic specimens ( 100 by 100 by $500 \mathrm{~mm}$ ) were prepared for each concrete mixture according to UNI 6555 [21]. After one day of wet curing, the specimens were stored at constant temperature $\left(20 \pm 2^{\circ} \mathrm{C}\right)$ and constant relative humidity $(50 \pm 2 \%)$ while measuring drying shrinkage at different curing times.

Finally, three cylindric specimens, $250 \mathrm{~mm}$ high with a diameter of $100 \mathrm{~mm}$, for each concrete mixture were manufactured for evaluating static modulus of elasticity in compression according to UNI 6556 [22].

\section{Results and Discussion}

3.1. Compression Test. Compressive strength was evaluated after 3 and 28 days of wet curing according to UNI EN 123903 [23] on cubic specimens, which were tested at right angles to the position of casting. The mean values obtained from fifteen specimens as well as the standard deviation values are reported in Table 4.

On the basis of the data reported in Table 4, whichever the kind of cement used, the substitution of 30\% virgin aggregate with coarse recycled concrete aggregate produced a loss of strength of about $20 \%$ after 28 days of wet curing.

Concerning the standard deviation values, they were practically independent on the type of aggregate used, showing that the same degree of homogeneity of the concrete 
TABLE 2: Mixture proportions of concretes made of 100\% virgin aggregates.

\begin{tabular}{|c|c|c|c|c|c|c|c|c|}
\hline Mixture & REF-I-0.40 & REF-II-0.40 & REF-I-0.45 & REF-I-0.50 & REF-II-0.50 & REF-I-0.55 & REF-I-0.60 & REF-II-0.60 \\
\hline Water/cement & 0.40 & 0.40 & 0.45 & 0.50 & 0.50 & 0.55 & 0.60 & 0.60 \\
\hline Water, kg & 140 & 140 & 153 & 165 & 165 & 176 & 186 & 186 \\
\hline Cement 42.5R, kg & 350 & - & 340 & 330 & - & 320 & 310 & - \\
\hline Cement 32.5R, kg & - & 350 & - & - & 330 & - & - & 310 \\
\hline Quartz sand, kg (\% in volume) & $732(40)$ & $732(40)$ & $723(40)$ & $715(40)$ & $715(40)$ & $708(40)$ & $702(40)$ & $702(40)$ \\
\hline Fine gravel, kg (\% in volume) & $553(30)$ & $553(30)$ & $547(30)$ & $541(30)$ & $541(30)$ & $535(30)$ & $531(30)$ & $531(30)$ \\
\hline Gravel, $\mathrm{kg}$ (\% in volume) & $556(30)$ & $556(30)$ & $549(30)$ & $543(30)$ & $543(30)$ & $537(30)$ & $533(30)$ & $533(30)$ \\
\hline $\begin{array}{l}\text { Superplasticizer, } \% \text { by weight of } \\
\text { cement }\end{array}$ & 1.2 & 1.2 & 1.0 & 0.8 & 0.8 & 0.6 & 0.4 & 0.4 \\
\hline
\end{tabular}

TABLE 3: Mixture proportions of concretes made of 30\% coarse recycled aggregates.

\begin{tabular}{|c|c|c|c|c|c|c|c|c|}
\hline Mixture & $\begin{array}{l}\text { CRA-I- } \\
0.40\end{array}$ & $\begin{array}{l}\text { CRA-II- } \\
0.40\end{array}$ & $\begin{array}{l}\text { CRA-I- } \\
0.45\end{array}$ & $\begin{array}{l}\text { CRA-I- } \\
0.50\end{array}$ & $\begin{array}{l}\text { CRA-II- } \\
0.50\end{array}$ & $\begin{array}{l}\text { CRA-I- } \\
0.55\end{array}$ & $\begin{array}{l}\text { CRA-I- } \\
0.60\end{array}$ & $\begin{array}{l}\text { CRA-II- } \\
0.60\end{array}$ \\
\hline Water/cement & 0.40 & 0.40 & 0.45 & 0.50 & 0.50 & 0.55 & 0.60 & 0.60 \\
\hline Water, kg & 140 & 140 & 153 & 165 & 165 & 176 & 186 & 186 \\
\hline Cement $42.5 \mathrm{R}, \mathrm{kg}$ & 350 & - & 340 & 330 & - & 320 & 310 & - \\
\hline Cement $32.5 \mathrm{R}, \mathrm{kg}$ & - & 350 & - & - & 330 & - & - & 310 \\
\hline Quartz sand, $\mathrm{kg}$ (\% in volume) & $732(40)$ & $732(40)$ & $723(40)$ & $715(40)$ & $715(40)$ & $708(40)$ & $702(40)$ & $702(40)$ \\
\hline Fine gravel, $\mathrm{kg}$ (\% in volume) & $553(30)$ & $553(30)$ & $547(30)$ & $541(30)$ & $541(30)$ & $535(30)$ & $531(30)$ & $531(30)$ \\
\hline $\begin{array}{l}\text { Coarse recycled aggregate, } \mathrm{kg} \text { ( } \% \text { in } \\
\text { volume) }\end{array}$ & $523(30)$ & $523(30)$ & $517(30)$ & $511(30)$ & $511(30)$ & $506(30)$ & $501(30)$ & $501(30)$ \\
\hline Superplasticizer, \% by weight of cement & 1.2 & 1.2 & 1.0 & 0.8 & 0.8 & 0.6 & 0.4 & 0.4 \\
\hline
\end{tabular}

TABLE 4: Compressive strengths (MPa) after 3 and 28 days.

\begin{tabular}{lcccc}
\hline $\begin{array}{l}\text { Curing times } \\
\text { Mixtures }\end{array}$ & Mean values & 3 days & \multicolumn{2}{c}{28 days } \\
REF-I-0.40 & 37.0 & Standard deviations & Mean values & 3.4 \\
REF-I-0.45 & 28.5 & 2.4 & 56.6 & 2.5 \\
REF-I-0.50 & 28.7 & 1.8 & 51.2 & 3.1 \\
REF-I-0.55 & 24.7 & 2.6 & 47.1 & 2.6 \\
REF-I-0.60 & 20.1 & 2.4 & 43.9 & 1.3 \\
REF-II-0.40 & 32.1 & 2.8 & 52.2 & 1.7 \\
REF-II-0.50 & 19.8 & 2.2 & 43.3 & 2.0 \\
REF-II-0.60 & 15.3 & 2.1 & 36.1 & 1.8 \\
CRA-I-0.40 & 29.7 & 1.9 & 46.1 & 3.2 \\
CRA-I-0.45 & 26.2 & 1.3 & 45.8 & 2.9 \\
CRA-I-0.50 & 22.2 & 1.7 & 39.9 & 3.7 \\
CRA-I-0.55 & 21.7 & 2.3 & 36.3 & 2.7 \\
CRA-I-0.60 & 15.5 & 1.7 & 34.7 & 1.6 \\
CRA-II-0.40 & 26.1 & 1.8 & 41.8 & 1.8 \\
CRA-II-0.50 & 16.4 & 1.6 & 35.1 & 1.8 \\
CRA-II-0.60 & 12.9 & 1.9 & 29.2 & 1.9 \\
\hline
\end{tabular}

mixtures could be achieved by using recycled aggregates instead of ordinary aggregates.

However, whichever the kind of cement used, RAC strength classes C 25/30 and C 28/35 can be confidently achieved, by keeping the water/cement under 0.60 and 0.50 , respectively, with cement type $42.5 \mathrm{R}$, and under 0.50 and 0.40 , respectively, with cement type $32.5 \mathrm{R}$.

On the other hand, RAC strength class C 32/40 can be achieved only by using cement type $42.5 \mathrm{R}$, by keeping the water/cement under 0.45 . 


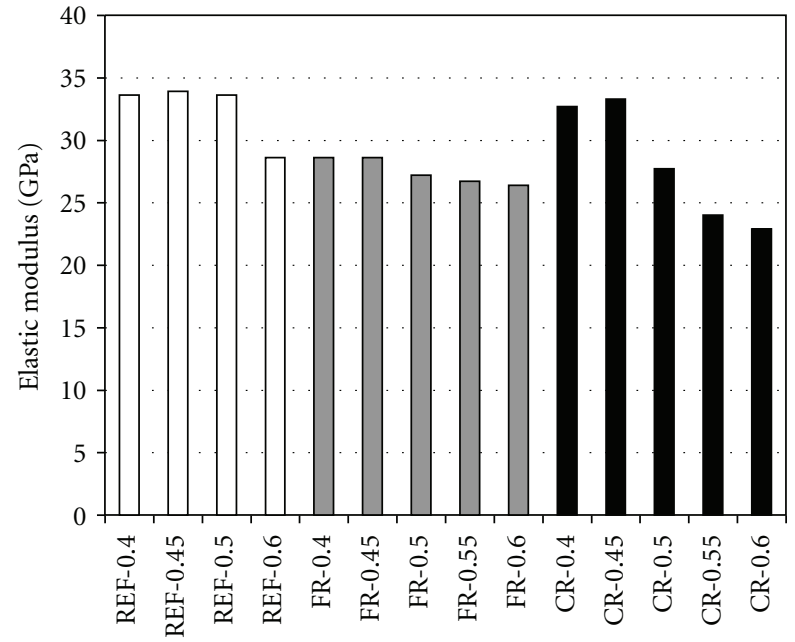

Figure 2: Static elastic modulus after 28 days of wet curing.

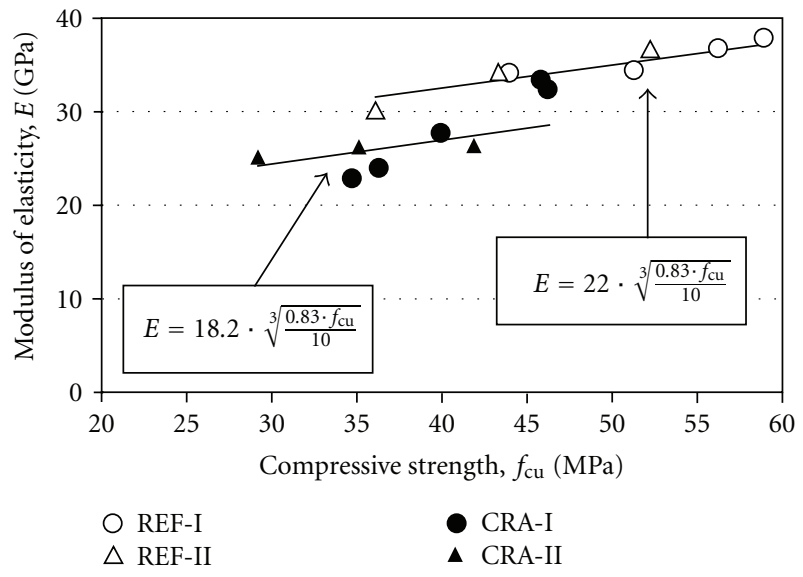

Figure 3: Static elastic modulus versus compressive strength after 28-days of wet curing.

3.2. Static Elastic Modulus Evaluation. Static modulus of elasticity was determined according to the procedure described in the Italian Standards UNI 6556 [22]. The mean values obtained after 28 days are shown in Figure 2 and plotted also in Figure 3 as a function of the concrete compressive strength after 28 days.

In Figure 3 two equations are reported:

$$
\begin{aligned}
& E=22.0 \cdot \sqrt[3]{\frac{0.83 \cdot f_{\mathrm{cu}}}{10}}, \\
& E=18.2 \cdot \sqrt[3]{\frac{0.83 \cdot f_{\mathrm{cu}}}{10}} .
\end{aligned}
$$

The first one (1) is the formula proposed by the Italian Standard [11] for regular concrete. Results obtained in this work on ordinary concretes showed to be in good agreement with (1).

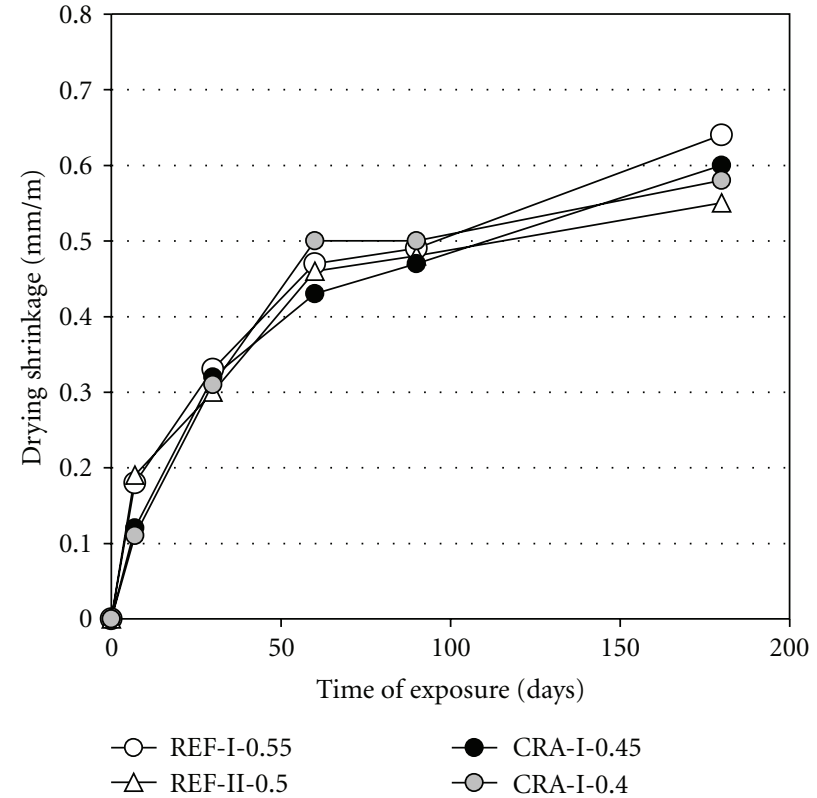

Figure 4: Drying shrinkage versus time of exposure for C 32/40 strength class concretes.

On the other hand, the second formula (2) was obtained by fitting experimental data obtained for the concrete mixtures prepared with $30 \%$ coarse recycled concrete aggregate, whichever the type of cement used.

In practice, it means that, for equal compressive strength, $17 \%$ lower elastic modulus is achieved by using 30\% coarse recycled aggregates. A similar result was obtained by the author in a previous work [10], in which a coefficient of 18.8 instead of 18.2 was found when the fine gravel $(6-12 \mathrm{~mm})$, instead of gravel (11-22 mm), was completely replaced by recycled concrete aggregate fraction $(6-12 \mathrm{~mm})$, also in that case the percentage of substitution was $30 \%$. This slight difference can signify a certain dependence of the RAC elastic modulus on the grain size of the recycled concrete aggregate used: the higher is the aggregate size the higher is the decrease with respect to the reference mixtures.

However, for practical uses a common coefficient equal to 18.5 can be suggested, independently on the recycled aggregate particle size, corresponding to $16 \%$ reduction of elastic modulus with respect to conventional concrete.

3.3. Drying Shrinkage Test. Drying shrinkage was evaluated according to UNI 6555 [21], results obtained up to 180 days of exposure are reported in Table 5.

In Figures 4, 5, and 6, three comparisons of the drying shrinkage strains of equal strength class concretes are shown. The compared mixtures were "REF-I-0.55," "REF-II-0.50," "CRA-I-0.40," and "CRA-II-0.45" for the strength class (see Table 4); "REF-I-0.60," "CRA-I-0.50," and "CRA-II-0.40" for the strength class (see Table 4) and "REF-II-0.60", "CRA-I-0.55" and "CRA-II-0.50" for the strength class (see Table 4). Results obtained on C 32/40, C 28/35, and C 25/30 
TABLe 5: Drying shrinkage measurements $(\mathrm{mm} / \mathrm{m})$.

\begin{tabular}{|c|c|c|c|c|c|}
\hline \multirow{2}{*}{ Mixture } & \multicolumn{5}{|c|}{ Days of exposure to $50 \%$ R.H., $20^{\circ} \mathrm{C}$ temperature } \\
\hline & 7 & 30 & 60 & 90 & 180 \\
\hline REF-I-0.40 & 0.09 & 0.26 & 0.34 & 0.4 & 0.44 \\
\hline REF-I-0.45 & 0.11 & 0.3 & 0.37 & 0.4 & 0.48 \\
\hline REF-I-0.50 & 0.19 & 0.27 & 0.43 & 0.45 & 0.5 \\
\hline REF-I-0.55 & 0.18 & 0.33 & 0.47 & 0.49 & 0.64 \\
\hline REF-I-0.60 & 0.24 & 0.34 & 0.48 & 0.58 & 0.7 \\
\hline REF-II-0.40 & 0.1 & 0.28 & 0.38 & 0.43 & 0.46 \\
\hline REF-II-0.50 & 0.19 & 0.3 & 0.46 & 0.48 & 0.55 \\
\hline REF-II-0.60 & 0.25 & 0.37 & 0.5 & 0.62 & 0.68 \\
\hline CRA-I-0.40 & 0.11 & 0.31 & 0.5 & 0.5 & 0.58 \\
\hline CRA-I-0.45 & 0.12 & 0.32 & 0.43 & 0.47 & 0.6 \\
\hline CRA-I-0.50 & 0.14 & 0.38 & 0.52 & 0.54 & 0.58 \\
\hline CRA-I-0.55 & 0.17 & 0.28 & 0.43 & 0.53 & 0.63 \\
\hline CRA-I-0.60 & 0.18 & 0.4 & 0.62 & 0.66 & 0.68 \\
\hline CRA-II-0.40 & 0.12 & 0.32 & 0.49 & 0.52 & 0.59 \\
\hline CRA-II-0.50 & 0.15 & 0.4 & 0.54 & 0.56 & 0.61 \\
\hline CRA-II-0.60 & 0.18 & 0.42 & 0.61 & 0.67 & 0.69 \\
\hline
\end{tabular}

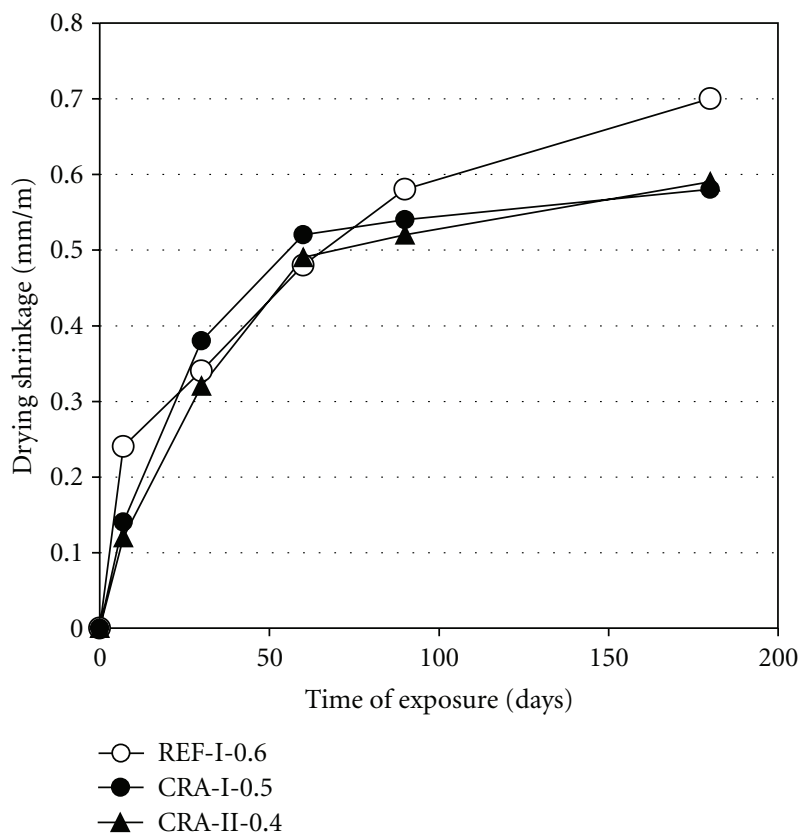

FIGURE 5: Drying shrinkage versus time of exposure for C 28/35 strength class concretes.

strength class concretes are reported in Figures 4, 5, and 6, respectively.

It can be noticed that, by using $30 \%$ coarse recycled aggregate, the values of the measured strains on RACs are similar (Figure 4), if not lower (Figures 5 and 6), to those obtained for the reference mixtures of the same strength class. Indeed, by comparing equal-strength concretes, the

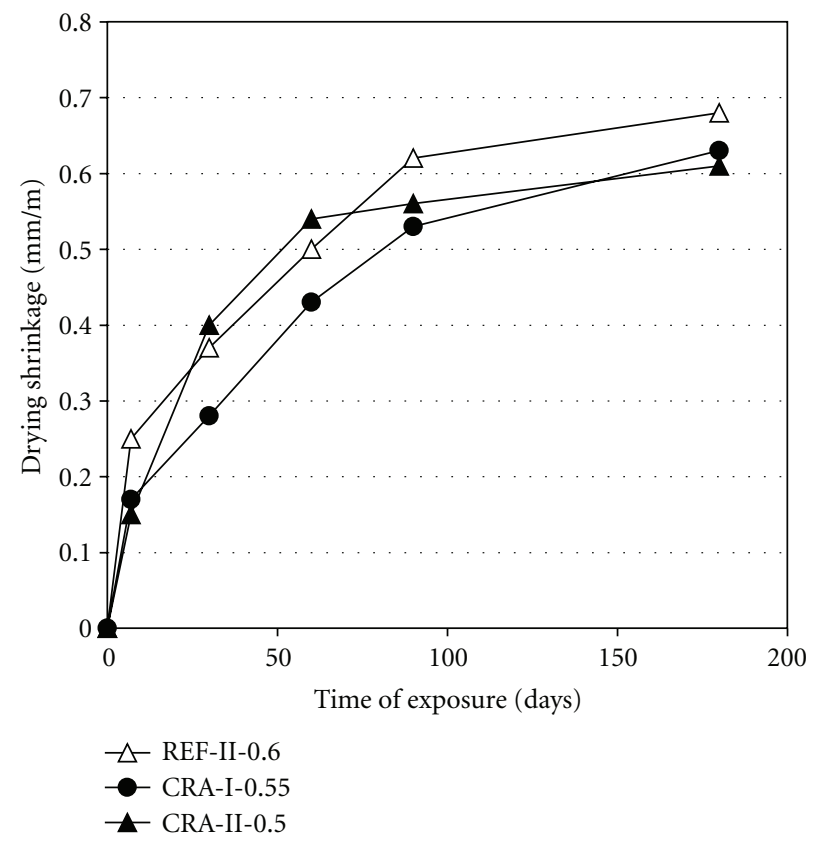

FIGURE 6: Drying shrinkage versus time of exposure for C 25/30 strength class concretes.

different kind of cement used seems to affect the drying shrinkage behavior of concrete more than the kind of aggregate used (see Figure 4), due to the different water-tocement ratios required to gain the same 28 -day compressive strength. 


\section{Conclusions}

Results obtained show that structural concrete up to C32/40 strength class can be manufactured by replacing 30\% virgin aggregate with coarse recycled-concrete aggregate.

Moreover, a correlation between elastic modulus and compressive strength of recycled-aggregate concrete was found showing that, in general, $16 \%$ lower elastic modulus is achieved by using 30\% coarse recycled aggregates, whatever the recycled aggregate grain size distribution.

Finally, on the basis of the results obtained by free drying shrinkage measurements, similar shrinkage behaviours are detected for equal-strength concretes, not depending on the kind of aggregate used. This last aspect, when considered together with a lower elastic modulus, predicts a lower tendency to crack appearance in RACs rather than in conventional concretes.

\section{References}

[1] "RILEM recommendation. 121-DRG guidance for demolition and reuse of concrete and masonry. Specifications for concrete with recycled aggregates," Materials and structures, vol. 27, pp. 557-559, 1994.

[2] ACI Committee 555, "Removal and reuse of hardened concrete," ACI Materials Journal, vol. 99, no. 3, pp. 300-325, 2002.

[3] K. Rahal, "Mechanical properties of concrete with recycled coarse aggregate," Building and Environment, vol. 42, no. 1, pp. 407-415, 2007.

[4] M. C. Limbachiya, E. Marrocchino, and A. Koulouris, "Chemical-mineralogical characterisation of coarse recycled concrete aggregate," Waste Management, vol. 27, no. 2, pp. 201-208, 2007.

[5] V. W. Y. Tam, K. Wang, and C. M. Tam, "Assessing relationships among properties of demolished concrete, recycled aggregate and recycled aggregate concrete using regression analysis," Journal of Hazardous Materials, vol. 152, no. 2, pp. 703-714, 2008.

[6] A. K. Padmini, K. Ramamurthy, and M. S. Mathews, "Influence of parent concrete on the properties of recycled aggregate concrete," Construction and Building Materials, vol. 23, no. 2, pp. 829-836, 2009.

[7] S. W. Tabsh and A. S. Abdelfatah, "Influence of recycled concrete aggregates on strength properties of concrete," Construction and Building Materials, vol. 23, no. 2, pp. 1163-1167, 2009.

[8] M. L. Berndt, "Properties of sustainable concrete containing fly ash, slag and recycled concrete aggregate," Construction and Building Materials, vol. 23, no. 7, pp. 2606-2613, 2009.

[9] M. Chakradhara Rao, S. K. Bhattacharyya, and S. V. Barai, "Influence of field recycled coarse aggregate on properties of concrete," Materials and Structures, vol. 44, pp. 205-220, 2011.

[10] V. Corinaldesi, "Mechanical and elastic behaviour of concretes made of recycled-concrete coarse aggregates," Construction and Building Materials, vol. 24, no. 9, pp. 1616-1620, 2010.

[11] NTC 2008, "Norme Tecniche per le costruzioni," D.M. $14 / 01 / 2008$.

[12] EN 197-1, "Cement-part 1: composition, specifications and conformity criteria for common cements,", 2000.

[13] EN 1097-6, "Tests for mechanical and physical properties of aggregates-determination of particle density and water absorption,", 2000.
[14] EN 933-1, "Tests for geometrical properties of aggregatesdetermination of particle size distribution—sieving method," , 1997.

[15] UNI EN 1744-1, “Tests for chemical properties of aggregateschemical analysis,", 1999.

[16] UNI 8520-22, "Aggregati per confezione di calcestruzzideterminazione della potenziale reattività degli aggregati in presenza di alcali (Aggregates for concretes-determination of potential alkali reactivity),", 2002.

[17] V. Corinaldesi and G. Moriconi, "Recycling of rubble from building demolition for low-shrinkage concretes," Waste Management, vol. 30, no. 4, pp. 655-659, 2010.

[18] EN 12350-2, “Testing fresh concrete-slump test,", 1999.

[19] J. Bolomey, "The grading of aggregate and its influence on the characteristics of concrete," Revue des Matériaux de Construction et Travaux Publiques, pp. 147-149, 1947.

[20] EN 12390-1, "Testing hardened concrete. Shape, dimensions and other requirements for specimens and moulds,", 2000.

[21] UNI 6555, "Concrete made with aggregate maximum size 30 mm," Hydraulic Shrinkage Determination, 1973.

[22] UNI 6556, "Tests of concretes-determination of static modulus of elasticity in compression,”, 1976.

[23] EN 12390-3, "Testing hardened concrete. Part 3: compressive strength of test specimens,", 2003. 

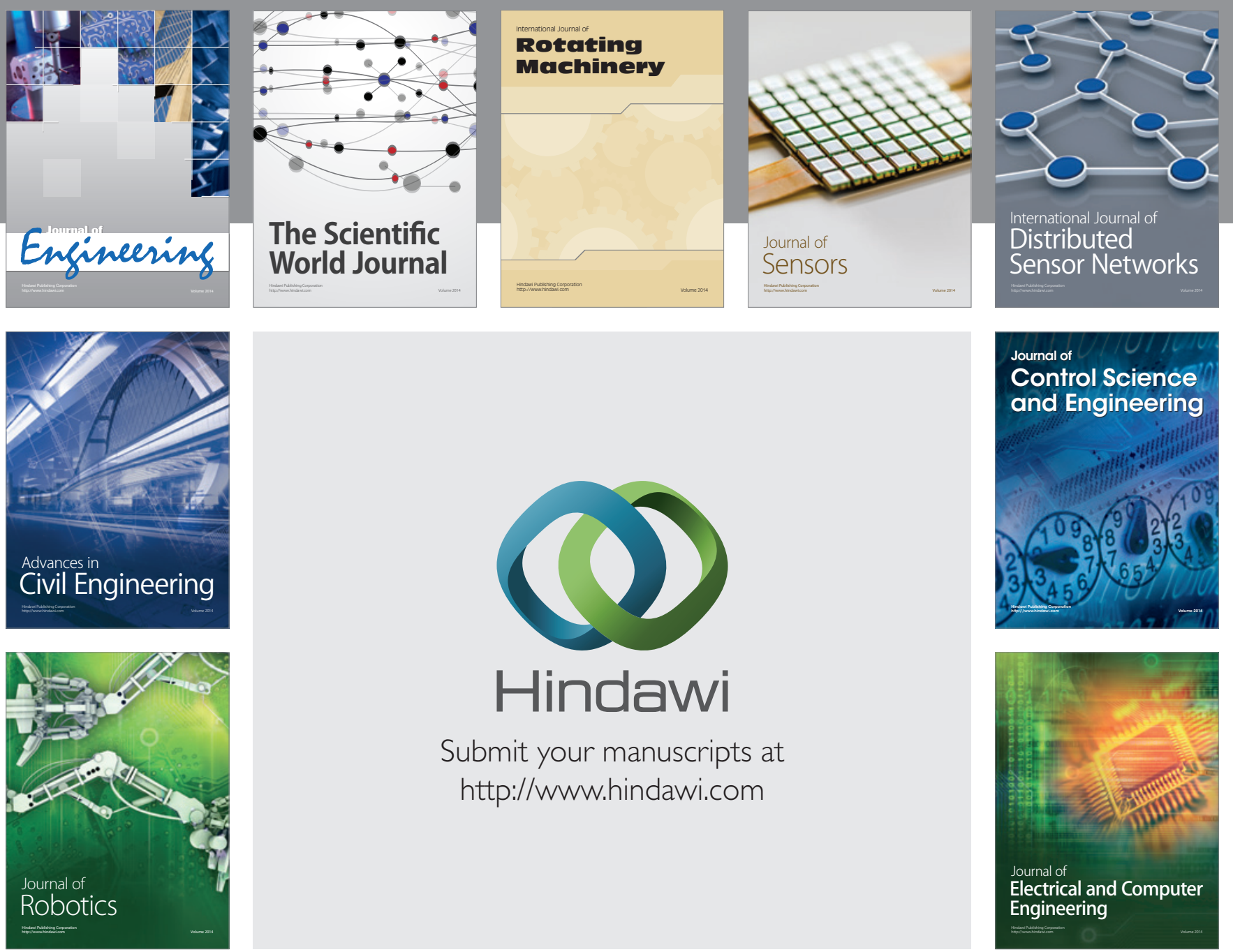

Submit your manuscripts at

http://www.hindawi.com
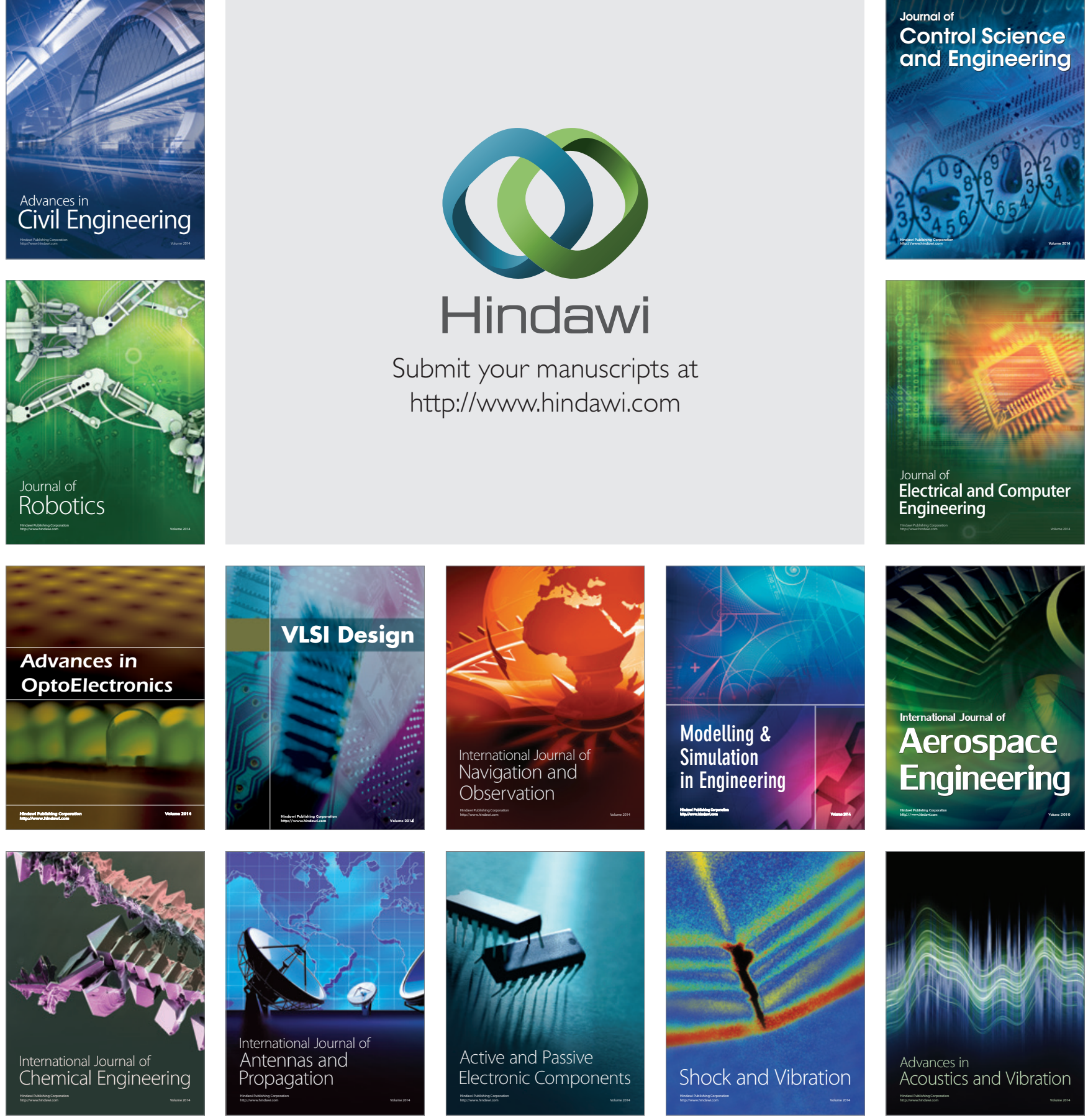